\title{
Knowledge attitude and practice of contraception among antenatal care patients
}

\author{
Radha Sangavi ${ }^{1 *}$, Shivappa Hatnoor ${ }^{2}$
}

\begin{abstract}
${ }^{1}$ Department of Obstetrics and Gynecology, ${ }^{2}$ Department of Preventative and Social Medicine, Raichur Institute of Medical Sciences, Raichur, Karnataka, India
\end{abstract}

Received: 26 June 2018

Accepted: 07 July 2018

\author{
*Correspondence: \\ Dr. Radha Sangavi, \\ E-mail: radhasangavi17@gmail.com
}

Copyright: () the author(s), publisher and licensee Medip Academy. This is an open-access article distributed under the terms of the Creative Commons Attribution Non-Commercial License, which permits unrestricted non-commercial use, distribution, and reproduction in any medium, provided the original work is properly cited.

\section{ABSTRACT}

Background: Strategies have been engaged by different governments in improving these indices amongst which is the use of family planning. Hence; authors planned the present study to assess the knowledge, attitude and practice of contraception among antenatal care patients.

Methods: A total of 100 patients were enrolled in the present study. With the help of structured anonymous selfadministered questionnaire, interviewing of the attendees of the antenatal clinic was done. The questionnaire was framed with aim of obtaining the clinical and demographic details of the subjects. All the data collecting interviews were conducted at the antenatal clinic. The participants were distributed a questionnaire and assistance given to any attendee with literal difficulty in filling the forms. The data obtained were collated in a purpose designed worksheet prepared for this study.

Results: 78 percent of the subjects were aware about contraception, while the remaining 22 percent of the subjects were unaware about contraception. Knowledge of subjects about barrier method of contraceptive was present in 78 subjects.

Conclusions: Antenatal women appear to have significant knowledge in relation to contraception.

Keywords: Antenatal, Attitude, Contraception, Knowledge

\section{INTRODUCTION}

One of the major global concerns is the health of mothers and children. Results from past researches have proved that perinatal, neonatal and under five as well as maternal mortality rates remain high in most developing countries. Strategies have been employed by various governments in improving these indices amongst which is the use of family planning. ${ }^{1}$ Despite employing this strategy, the contraceptive prevalence is relatively low in most developing countries with values ranging from 6-14.6\%. In relation to the non-utilization of modern contraception, the major obstacles include fear of side effects, poor quality of services and opposition from family members or influential 10 members of the community. ${ }^{2}$ The likelihood of infants dying before their first birth day has been demonstrated to be far greater if the infant was born less than one year after the end of their mothers' last pregnancy than those born after a longer interval. ${ }^{3}$ Improved outcome of infants are noted to be better, if the mothers waited for 18 to 23 months, after a full term birth and before conceiving again. This highlights the requirement for contraceptive use immediately after the postpartum time as this period characterizes the beginning of return of fertility in most females. The Antenatal clinic was selected as the present study area as it suggests the best environment within the hospital for 
meeting females in the reproductive age group along with providing a forum for dissemination of family planning information, correction of wrong perceptions as well as the opportunities for exchange of ideas between mothers. ${ }^{4-8}$ Hence; authors planned the present study to assess the knowledge, attitude and practice of contraception among antenatal care patients.

\section{METHODS}

A total of 100 patients were enrolled in the present study. The study was conducted in the Department of Obstetrics and Gynaecology, RIMS, Raichur. It included assessment of the knowledge, attitude and practice of contraception among antenatal care patients. Ethical approval was obtained from institutional ethical committee and written consent was obtained after explaining in detail the entire research protocol.

\section{Inclusion criteria}

- Pregnant women attending Antenatal clinic.

- Women between the age group of 20 to 40 years.

- Women with negative history of any known systemic illness or co-morbid condition.

- Women with negative history of any hormonal disorder.

With the help of structured anonymous self-administered questionnaire, interviewing of the attendees of the antenatal clinic was done. The questionnaire was framed with aim of obtaining the clinical and demographic details of the subjects. Authors also collected information in relation to the reproductive health data of the subjects, awareness of time of commencement of contraceptive choices, knowledge of different variety of contraceptive techniques, information's source, and explanations about use and none use of contraceptive techniques. All the data collecting interviews were conducted at the antenatal clinic. The participants were distributed a questionnaire and assistance given to any attendee with literal difficulty in filling the forms. The data obtained were collated in a purpose designed worksheet prepared for this study. Data collected were analysed with EPI info 2000 computer software. The results were presented percentages, means, tables and charts.

\section{RESULTS}

In the present study, majority of the subjects were more than 30 years of age approximate 43 subjects were aged between 31-35 year, 38 subjects were older than 35 year of age ant it is found in the present study only 2 subjects were less than 25 years of age. Parity was found to be in between one to four in 70 percent of the patients, in $26 \%$ it was 0 and in $4 \%$ patients $=5$. It was also found that 8 patients were uneducated, 6 patients had there only primary education,30 till secondary ,54 percent of the subjects were graduates and only 2 were (Table 1 ).
Table 1: Demographic and clinical details of the subjects.

\begin{tabular}{|c|c|c|}
\hline Parameter & & Number \\
\hline \multirow{4}{*}{$\begin{array}{l}\text { Age group } \\
\text { (years) }\end{array}$} & Less than 25 & 2 \\
\hline & $26-30$ & 17 \\
\hline & $31-35$ & 43 \\
\hline & More than 35 & 38 \\
\hline \multirow{3}{*}{ Parity } & 0 & 26 \\
\hline & $1-4$ & 70 \\
\hline & $=5$ & 4 \\
\hline \multirow{5}{*}{$\begin{array}{l}\text { Educational } \\
\text { qualification }\end{array}$} & Uneducated & 8 \\
\hline & Primary education & 6 \\
\hline & Secondary education & 30 \\
\hline & Graduate & 54 \\
\hline & Postgraduate & 2 \\
\hline
\end{tabular}

Table 2 shows Awareness of the subjects towards contraception 78 percent of the subjects were aware about contraception, while the remaining 22 percent of the subjects were unaware about contraception whereas 66 subjects and 34 were unaware, $60 \%$ subjects aware of benefits of birth spacing whereas $40 \%$ were unaware.

Table 2: Awareness of the subjects.

\begin{tabular}{|lll|}
\hline Awareness & $\begin{array}{l}\text { Aware } \\
\text { (No. of } \\
\text { sulbjects) }\end{array}$ & $\begin{array}{l}\text { Unaware } \\
\text { (No. of } \\
\text { sulbjects) }\end{array}$ \\
\hline Aware of contraception & 78 & 22 \\
\hline $\begin{array}{l}\text { Aware about need of limiting } \\
\text { child birth/ birth spacing }\end{array}$ & 66 & 34 \\
\hline $\begin{array}{l}\text { Aware of benefits of birth } \\
\text { spacing }\end{array}$ & 60 & 40 \\
\hline
\end{tabular}

Table 3 demonstrates knowledge of subjects about types of contraceptive methods, $78 \%$ subject given response to using contraceptive barrier and $64 \%$ combined with oral contraceptive pills, $2 \%$ patients not given any response on barrier and $3 \%$ patients not given response on oral contraceptive pills.

Table 3: Knowledge of subjects about types of contraceptive methods.

\begin{tabular}{|lll|l|}
\hline Parameter & $\begin{array}{l}\text { Yes } \\
\text { (No. of } \\
\text { subjects) }\end{array}$ & $\begin{array}{l}\text { No } \\
\text { (No. of } \\
\text { sulbjects) }\end{array}$ & $\begin{array}{l}\text { Nosponse } \\
\text { reso. of } \\
\text { sulbjects) }\end{array}$ \\
\hline Barrier & 78 & 20 & 2 \\
\hline $\begin{array}{l}\text { Combined oral } \\
\text { contraceptive pills }\end{array}$ & 64 & 33 & 3 \\
\hline
\end{tabular}

\section{DISCUSSION}

Contraception is defined as the prevention of conception or impregnation by methods other than abstinence from coitus. Various methods of contraceptives exist, each with its own advantages and disadvantages. An ideal 
contraceptive should be completely effective, reversible, convenient, simple, cheap, acceptable and safe. Studies in developing countries have shown low frequencies of contraceptive use despite the high level of awareness. ${ }^{6}$ Hence; authors planned the present study to assess the knowledge, attitude and practice of contraception among antenatal care patients.

In the present study, authors observed that 78 percent of the subjects were aware about contraception, while the remaining 22 percent of the subjects were unaware about contraception. Allagoa DO et al determined the knowledge, attitude and practice of contraception among antenatal clinic attendees in the University of Port Harcourt Teaching Hospital. A total of 300 questionnaires were administered and 253 were retrieved. Majority of the respondents $234(92.5 \%)$ were aware of contraceptive usage. $38.7 \%$ of respondents had knowledge of the use of Lactation amenorrhoea method as a form of contraception. Amongst $26.5 \%$ of attendees who had used a contraceptive option previously the condom was the commonest contraceptive used. ${ }^{7,8}$ The antenatal Clinic was the source of contraceptive knowledge in $79 \%$ of the respondents. The commonest reason for use of contraceptive method was for child spacing while the fear of complication was the commonest cause of none use. The contraceptive awareness amongst women attending antenatal clinic was high without corresponding increase in usage of available methods. ${ }^{1}$

Busery $\mathrm{S}$ et al and Rahman $\mathrm{A}$ et al assessed the knowledge, attitude and practice of emergency contraceptive use among graduating female students of College of Health and Medical Sciences (CHMS), Haramaya University (HU). Institutional based crosssectional study was conducted from April 1-April 30, 2015. The calculated sample size of 130 was evenly stratified to each department graduating female students. Simple random sampling was then employed to collect data from each stratum using self-administered questionnaire. One hundred twenty-five have heard of EC. The common sources of information were teachers in class 50, health institutions 45 and mass media 15 . Coming to the attitude of the respondents towards ECs, 78 agreed and 31 strongly agreed that ECs prevent unwanted pregnancy after unprotected sex. Fifty-five agreed to use EC in the future. Regarding the actual practice, from 59 students who had sexual intercourse, only 36 used oral post coital pills. The awareness of the students towards ECs was found to be appreciable. However, as health and medical science college students, the practice of EC was not as such promising. ${ }^{9,10}$ Utoo BT et al determined the knowledge, attitude and use of family planning methods among women attending antenatal clinic in Jos; factors that militates against use of contraceptive methods and their contraceptive intentions following the index pregnancy. This was a cross-sectional study involving 420 women who attended the antenatal clinic. The respondents were interviewed by the use of structured interviewer administered questionnaire. Knowledge and acceptability of family planning methods were high, while modern family planning methods use was $44.0 \%$. More women $39.3 \%$ were aware of oral contraceptive pills. Common methods used were male condom $(59.5 \%)$, oral contraceptive pills $(47.0 \%)$ and injectables $(27.1 \%)$ among others. Most of the women $(60.0 \%)$ received their family planning information in the hospital. Seventy five percent of the women agreed that both husband and wife should jointly decide for a family planning method. Sixty eight percent of women would like to use contraceptive methods after delivery of the index pregnancy. The desire for more children accounted for $36.5 \%$ among those that refused use of contraceptive method after delivery. Despite the high educational status, knowledge and acceptability of family planning methods observed in their study, the practice of these methods is still relatively low. More targeted and wellorganized educational campaigns are needed to improve this trend. ${ }^{11}$ Olamijulo JA et al examined the sociodemographic data of antenatal clinic attendees at the Lagos University Teaching Hospital (LUTH), their knowledge about contraceptive methods, previous contraceptive practice and anticipated pattern of postpartum contraceptive uptake. Sixty women, in their study, stopped using contraceptive because they wanted to get pregnant. Sixty-eight women planned to use contraceptives after delivery and the male condom was the most preferred method of post-partum contraception. There is no statistical association between age, religion, parity and educational attainment and desire for postpartum contraception. Antenatal women in LUTH appeared quite knowledgeable about contraception but majority had no plan for contraceptive use postdelivery. ${ }^{11-13}$

\section{CONCLUSION}

From the above results, the authors conclude that antenatal women appear to have significant knowledge in relation to contraception. However; future studies are recommended.

Funding: No funding sources Conflict of interest: None declared

Ethical approval: The study was approved by the Institutional Ethics Committee

\section{REFERENCES}

1. Chandna A, Nath J, Dhingra D. Awareness of emergency contraception among 1st year medical students. Int J Contemp Med Res. 2016;3(6):156870.

2. Bijeta, Nalini N. Medical method of second trimester abortion: mifepristone plus misoprostol vs misoprostol alone. Int $\mathbf{J}$ Contemp Med Res. 2017;4(12):4-6.

3. Maternal Mortality: Helping women off the road to death. Report of the inter-regional meetings on the 
prevention of maternal mortality. WHO chronicle, 1986;40(5):175-83.

4. Olatunji AD, Abudu, OO. A review of maternal mortality in LUTH. Nigerian Med Practitioner. 1996;31(2):2-6.

5. Ogedengbe OK, Giwa OF, Adeboye M, Lisi CA. The acceptability and role of norplant as a long acting contraceptive in Lagos, Nigeria. Trop J Obstet Gynaecol. 1997;14(1):28-32.

6. Khan T, Khan RE. Fertility behavior of women and their house hold characteristics-A case study of Punjab Pakistan. J Hum Ecol. 2010;30:11-7.

7. Jabeen M, Gul F, Wazir F, Javed N. Knowledge, attitude and practices of contraception in women of reproductive age. Gomal J Med Sci. 2011;9:223-9.

8. Ankomah A, Anyanti J, Adebayo S, Giwa A. Barriers to contraceptive use among married young adults in Nigeria: A qualitative study. Int $\mathbf{J}$ Trop Dis Health. 2013;3:267-82.

9. Rahman A, Rahman M, Zaman JA. Contraceptive practice among the married women of reproductive age in the garments factory. KYAMC J. 2013;3:2829.
10. Busery S, Sisay M. Knowledge, attitude and practice of emergency contraceptives among graduating female students of college of health and medical sciences, Haramaya University, Eastern Ethiopia. Sch Acad J Pharm. 2016;5(12):413-20.

11. Utoo BT, Mutihir TJ, Utoo PM. Knowledge, attitude and practice of family planning methods among women attending antenatal clinic in Jos, Northcentral Nigeria. Niger J Med. 2010 AprJun;19(2):214-8.

12. Olamijulo JA, Olorunfemi G. Knowledge and practice of contraception among pregnant women attending the antenatal clinic in Lagos University Teaching Hospital. Niger J Med. 2012 OctDec;21(4):387-93.

13. Prasad D, Smita KS, Nisha S. Vitamin D in pregnancy and its correlation with feto maternal outcome. Int J Contemp Med Res. 2018;5(1):1-5.

Cite this article as: Sangavi R, Hatnoor S.

Knowledge attitude and practice of contraception among antenatal care patients. Int J Reprod Contracept Obstet Gynecol 2018;7:3065-8. 